\title{
THE STUDY OF STAB RESISTANCE OF DRY ARAMID FABRICS
}

\author{
Wiesław BARNAT*, Dariusz SOKOŁOWSKI ${ }^{\star}$ \\ *Faculty of Mechanical Engineering, Department of Mechanics and Applied Computer Science, Military University of Technology,
} ul. Kaliskiego 2, 00-908 Warszawa, Poland,

\author{
wbarnat@wat.edu.pl, dsokolowski@wat.edu.pl
}

\begin{abstract}
The paper presents the issue of a knife proof ballistic package. This issue was emphasized since most of modern vests are designed to match the threat posed to them only by firearms. There was observed negligence of protection against melee attacks. There is, thus, a need to develop a research methodology in this matter, because it is a valid and necessary problem in a modern developed society. The aim of this study was to perform a numerical model which simulated the phenomenon of penetration of a ballistic package by an engineering blade. Specification of an engineering blade was taken from standard NIJ Standard-0115.00. Commercial software LSDYNA was used to carry out the analysis.
\end{abstract}

Key words: Numerical Model, Dry Fabric, FEM, Aramid Fabric, Composite

\section{INTRODUCTION}

The paper presents the issue of a knife proof ballistic package This issue was emphasized since most of modern vests are designed to match the threat posed to them only by firearms. There was observed negligence of protection against melee attacks. There is, thus, a need to develop a research methodology in this matter, because it is a valid and necessary problem in a modern developed society (Johnson et al., 2012, Horsfall, 2000).

A number of firearms on Polish streets is not so large compared to, for example, the United States. Polish legislation is effectively concerned about a restricting access to firearms for people with inappropriate predispositions. As for the melee weapons, the case is diametrically different. An access to melee weapons is unlimited. Each kitchen has a whole arsenal of objects that can be used as a weapon against the officers of the uniformed services.

The aim of this study was to perform a numerical model which simulates the phenomenon of penetration of a ballistic package by an engineering blade. The engineering blade was taken from standard NIJ Standard-0115.00 (U.S. Department of Justice, (2000). Commercial software LS-DYNA was used to carry out the analysis.

The problem was solved using the method of explicit integration of the equations of motion.

\section{DESCRIPTION OF THE ISSUE}

To prepare a numerical model describing penetration of a ballistic package by an engineering blade, dry Aramid fabric has been selected. The specification of the fabric has been taken from manufacturer data ECC. The blade was modeled as a perfectly rigid body, since the plastic effects do not occur on the blade during the impact.
A sample of the ballistic package used to numerical tests was a circle of a diameter of $100 \mathrm{~mm}$. The assumed package thickness was equal to $3.5 \mathrm{~mm}$, which corresponds to 12 layers of dry aramid fabric ECC Style328. A size of the sample was taken from the standards described above. A number of layers was chosen arbitrarily to recognize opportunities representation of the phenomena and to work out the methodology of FEM model construction.

Blade energy also was taken from the standard quoted above and was determined at about $36 \mathrm{~J}$, at a speed of $V=166 \mathrm{~m} / \mathrm{s}$ (the speed was increased due to numerical reasons - in order to reduce computation time). In the final model, there will be used speed $V=6 \mathrm{~m} / \mathrm{s}$ with unchanged kinetic energy. Such a speed change should not influence the physics of the phenomenon, because the energy of the object is constant. In addition, the standard specifies only the kinetic energy of the blade, without giving speed.

\section{THE NUMERICAL MODEL}

In the model, there was mapped dry aramid fabric produced by ECC (ECC Style 328) and made of Kevlar 49. Arial density of fabric is about $230 \mathrm{~g} / \mathrm{m} 2$. A volume share ratio of Kevlar fibers in the bundle was calculated (based on manufacturer's material cards) at $30 \%$ of bundle volume. Placeholder Young's modulus was determined using the law of mixtures taken from literature for the assumed rate of volume (Jones, 1999).

$E_{11}=E_{W} V_{W}+E_{0}\left(1-V_{W}\right)$

where: $E_{11}$ - Young module in direction of bundle, $E_{W}-$ Young module of Kevlar $49, V_{W}$ - volume ratio, $E_{0}$ - matrix Young module (assumed as equal to zero)

The density of the bundle was reduced and it is $30 \%$ of density of Kevlar. The coefficient of friction, which was adopted, was equal to $\eta=0.1$. 
Fig. 1 shows a sample of a ballistic package and an engineering blade "S1". The a square outline in the center of the sample is the area of accurate modeling of dry aramid fabric. This area of the fabric has been modeled as a weave of roving bundles. Each roving bundle was modeled as a band of "shell" elements (Fig. 2.). Between roving bundles, there were defined contact pairs, as well as between a knife and the bundles of roving. A type of implemented contacts was "CONTACT_AUTOMATIC_ SURFACE_TO_SURFACE”. A type of the used material that was used was „003-MAT_PLASTIC_KINEMATIC".

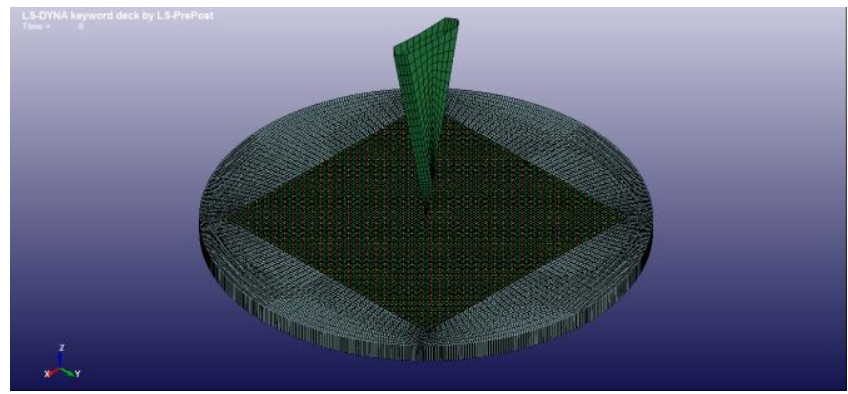

Fig. 1. Isoperimetrical view of engineering blade and ballistic package

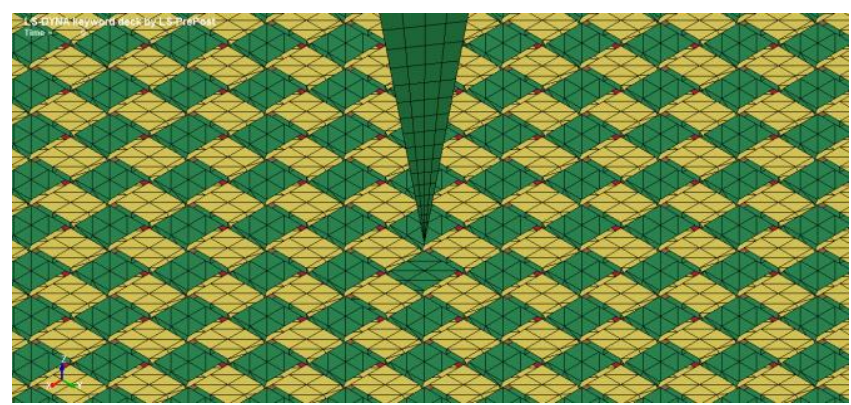

Fig. 2. Isoperimetrical view of engineering blade and ballistic package - zoomed

The remaining part of the sample was a coarse model that has been made in the traditional way using membrane elements. The thickness of the coarse area is equal to the thickness of the fabric. The used material model was "059-MAT_COMPOSITE FAILURE_SHELL_MODEL". This type of material has been used, because during modeling of the dry fabric, there is a need to reduce the Kirchhoff module in the plane of the fabric to a very small value. It results from not transferring the shear in the plane of the fabric through the fabric_which is not laminated. At the periphery of the coarse model, there has been removed translational degrees of freedom $\left(U_{x}, U_{y}, U_{z}\right)$.

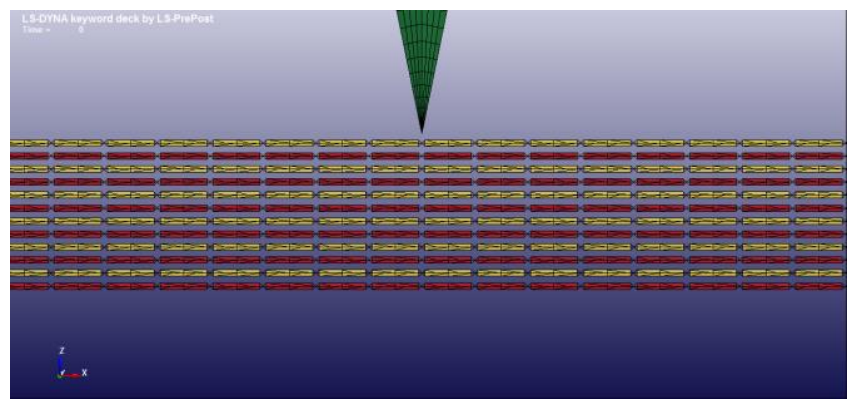

Fig. 3. View of blade and modeled fabric in the plane of the fabric
Fig. 3 shows a section through a ballistic package, it can be observed that the package contains 12 layers stacked on each other. Between the layers, there were defined contact pairs. Each layer has a defined contact with the blade. The geometry of the engineering blade was modeled in an accurate, ideal manner. It means that the dimensions are modeled without deviations, and the blade ends in a point. The blade, to perform the worst case, due to the penetration of a ballistic package, has been placed between the bundles, in the longitudinal and transverse direction of samples.

The maximum time of calculation was set arbitrarily at the moment when the knife blade fully penetrates a ballistic insert.

\subsection{Model 1 - Balistic Package in the Form of Dry Aramid Fabric ECC Style 328 [0]}

In the first studied model, the layers were arranged in one direction. This method of laying the layers of ballistic packages is widespread. It resulted from process conditions, namely, ease of arrangement. A disadvantage of such a solution is the fact that the working bundles are located in two lanes intersecting at the point of impact of the knife.

This section will also discuss the results obtained from this model.

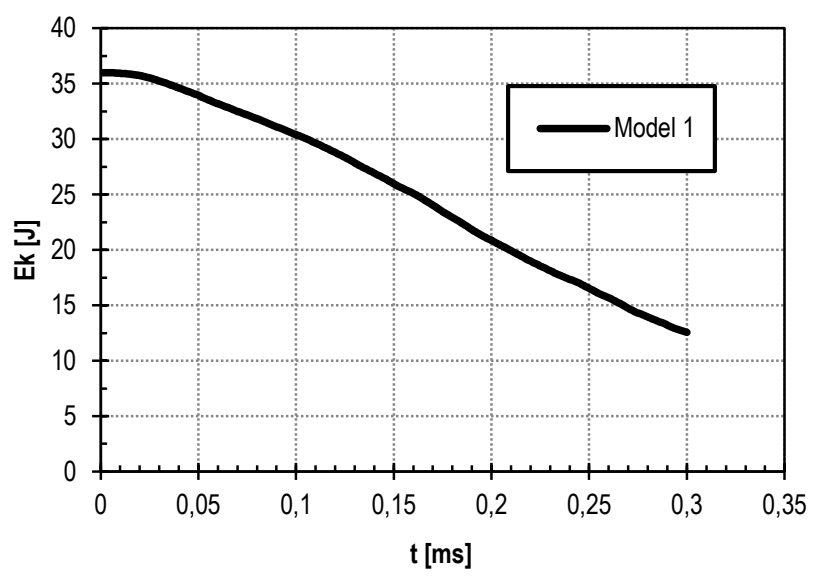

Fig.4 . Kinetic energy of blade in model 1

Fig 4. shows kinetic energy of the blade. The chart is continuous, no abrupt changes of the kinetic energy descent are observed. It means that the contact model worked properly in the first instant of time. In other words, the contact has been properly established.

During eroding of the elements, successive elements smoothly came into contact with the knife and kept it propped. Energy was dissipated to work against the forces of elasticity of the material of the package and eroding elements.

At $t=0.0003 \mathrm{~s}$ kinetic energy of the blade dropped to the level of approximately $12.56 \mathrm{~J}$.

Fig. 5 shows a situation when a knife punctured the ballistic package and deformed it. It can be observed that the contacts between each of the bundles, and each bundle with a knife has been established correctly.

Fig. 6 presents a top view after removal of the knife. It can be observed how the fibers on the horizontal direction were spread 
apart to the sides and broken. The same situation occurred in the case of the bundles on the vertical direction.

Fig. 7 show the equivalent tensile stresses. The maximum values are equal to $3200 \mathrm{MPa}$. It is observed that the area around the blade is loaded evenly.

Fig. 8 shows strain at time $\mathrm{t}=0.0001 \mathrm{~s}$, the maximum strain is $2.3 \%$, after gaining this value the element was eroded.

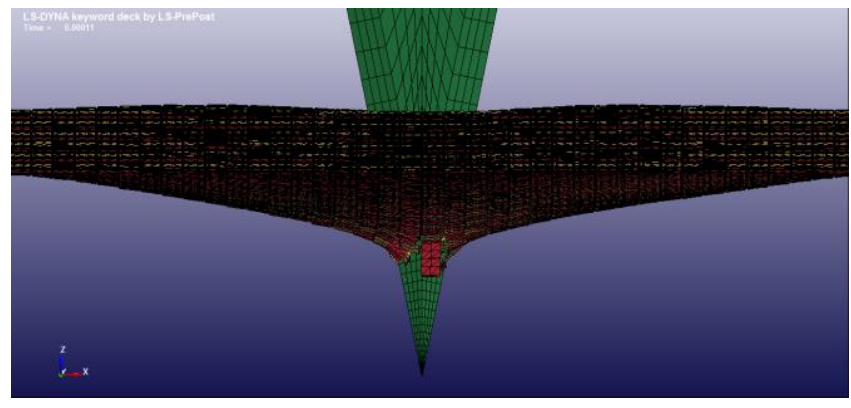

Fig. 5. Ballistic package punctured by blade in time $t=0,0001 \mathrm{~s}$

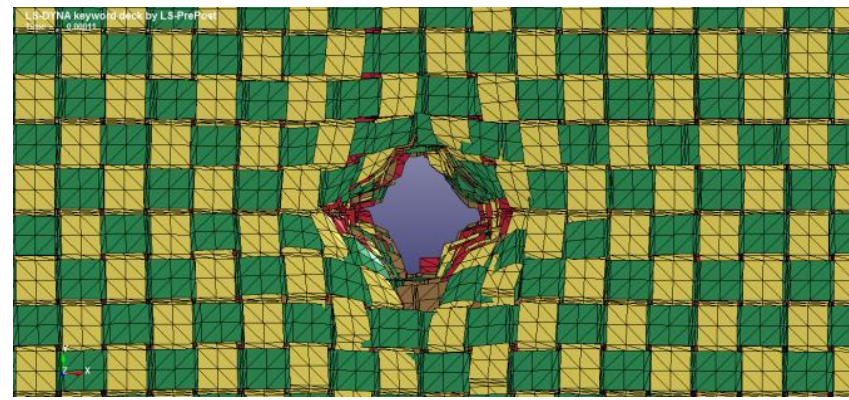

Fig. 6. Ballistic package punctured by blade $t=0.0001 \mathrm{~s}-$ top view

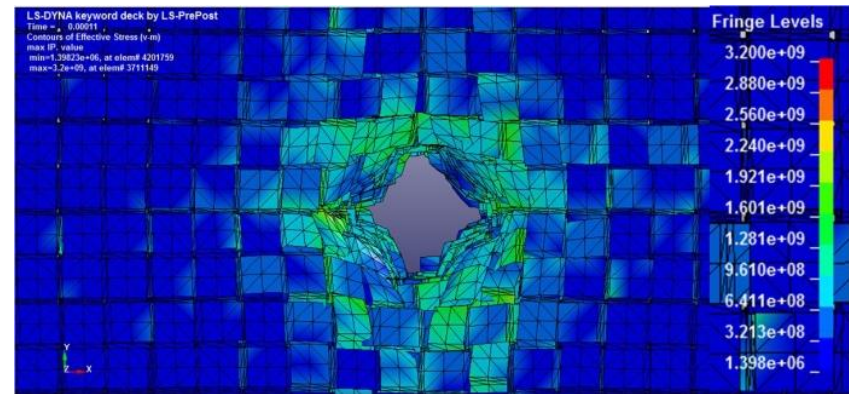

Fig. 7. Equivalent tensile stresses in the ballistic package $t=0.0001 \mathrm{~s}$ - top view

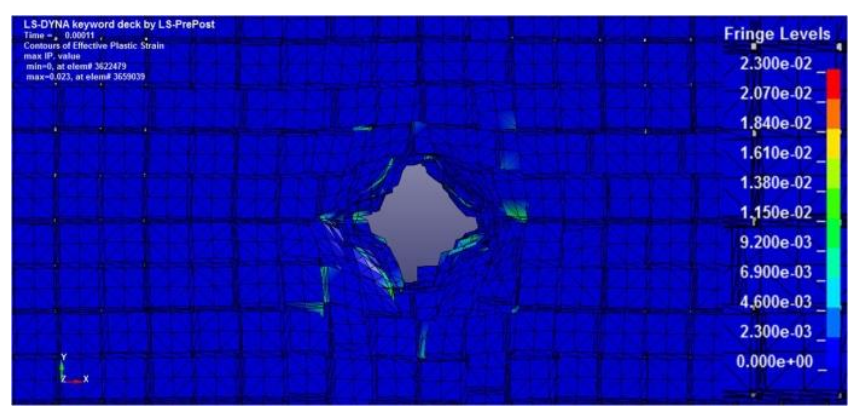

Fig. 8. Plastic strains in ballistic package $t=0.0001 \mathrm{~s}-$ top view

\subsection{Model 2 - Balistic Package in the Form of Dry Aramid Fabric ECC Style 328 [00/45이}

In the second model, the layers are arranged in two main directions: $0^{0}$ and $45^{\circ}$. This arrangement allows for the inclusion of other areas of the package to work. Owing to this fact, the package runs smoothly. The disadvantage of this approach is a more complicated manufacturing process.

a)

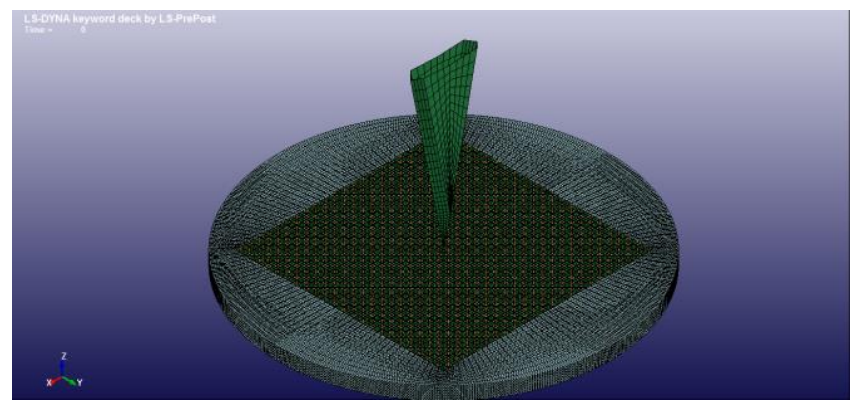

b)

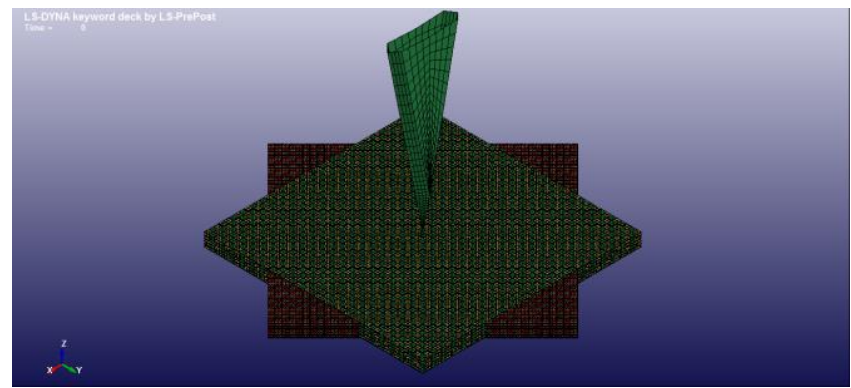

Fig. 9. Isoperimetrical view of engineering blade and ballistic package a) together with the coarse area, b) without coarse area

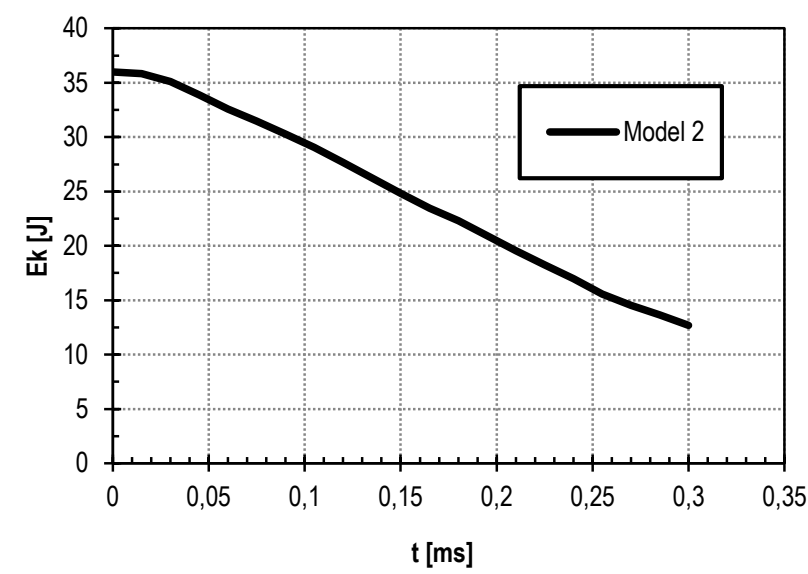

Fig. 10. Kinetic energy of blade in model 2

Fig. 10 shows kinetic energy of the blade. The chart is continuous, no abrupt changes of the kinetic energy descent are observed. It means that the contact model worked properly in the first instant of time. In other words, the contact has been properly established.

During eroding of the elements, successive elements smoothly came into contact with the knife and kept it propped. Energy was dissipated to work against the forces of elasticity of the material of the package and eroding elements. 
At $t=0.0003 \mathrm{~s}$ kinetic energy of the blade dropped to the level of approximately 12.68J.

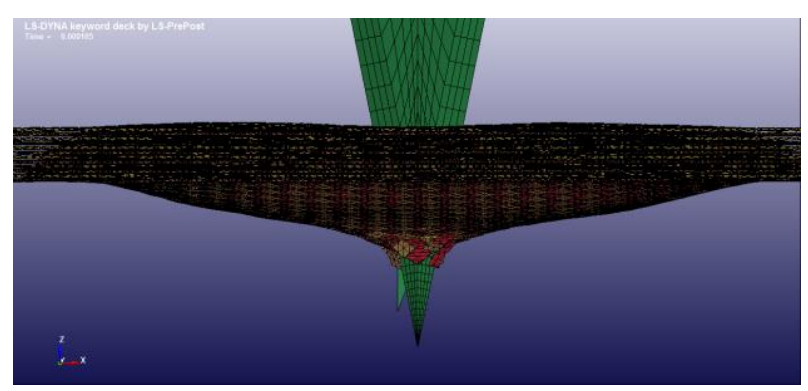

Fig. 11. Ballistic package punctured by blade in time $t=0.0001 \mathrm{~s}$

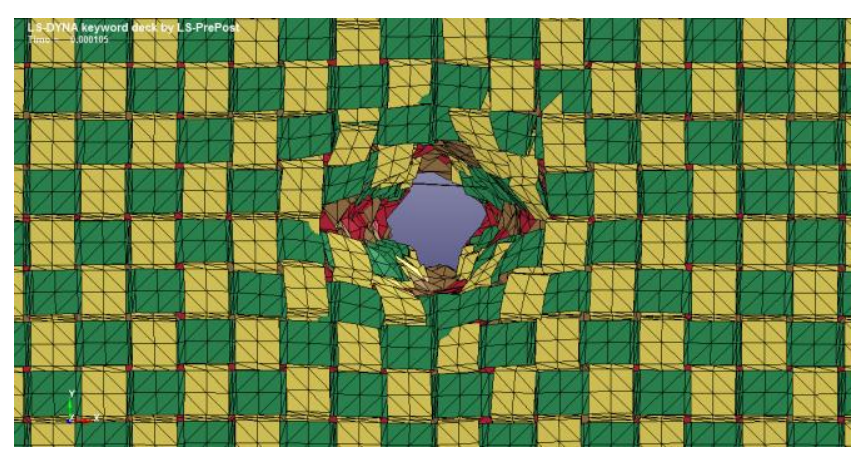

Fig. 4. Ballistic package punctured by blade $t=0.0001 \mathrm{~s}-$ top view

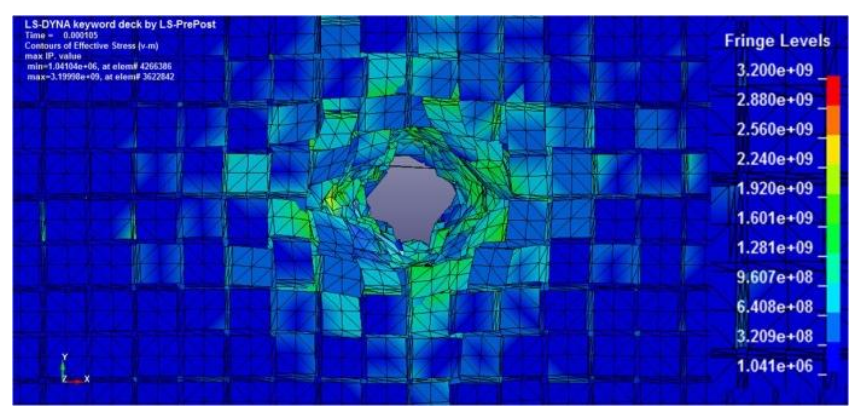

Fig. 5. Equivalent tensile stress in the ballistic package $t=0.0001 \mathrm{~s}$ - top view

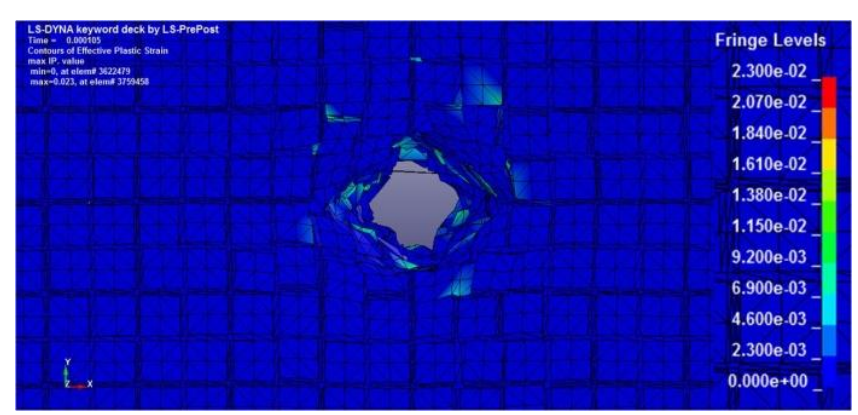

Fig. 6. Plastic strains in ballistic package $t=0.0001 \mathrm{~s}-$ top view

\subsection{Model 3 - Balistic Packege in the Form of dry Aramid Fabric ECC Style 328 [00/22.50/450/67.50]}

In model 3, the fabric is arranged in four directions: $0^{0}, 22.5^{\circ}$, $45^{\circ}$ and $67.5^{\circ}$. Such a structure of a ballistic package makes almost the entire structure work in $360^{\circ}$. A weakness of this ap- proach is a complex arrangement technology in relation to the classical unidirectional approach.

a)

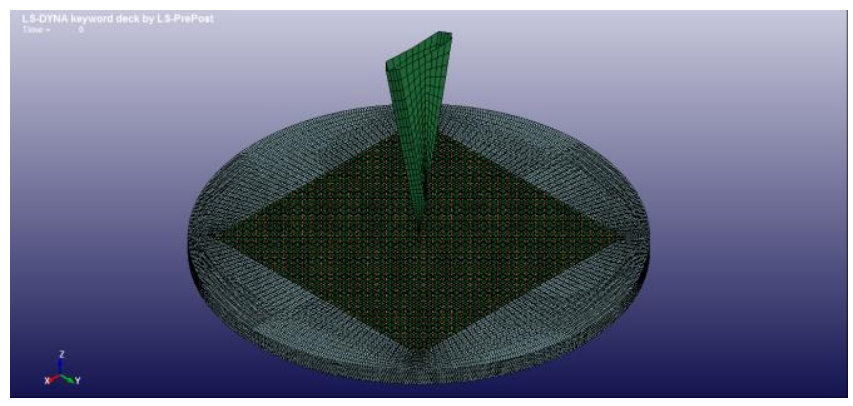

b)

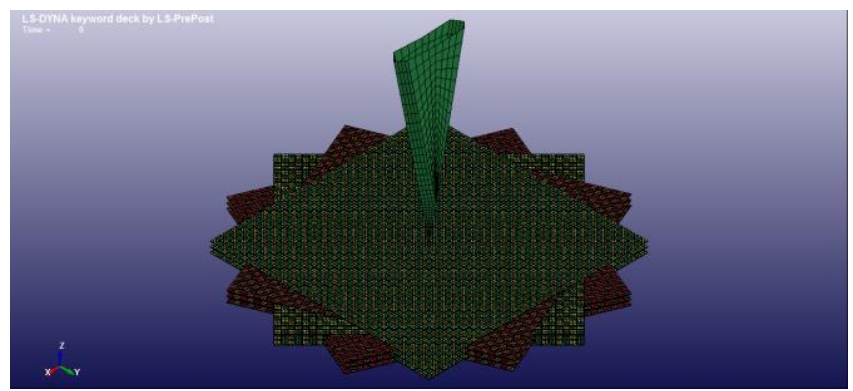

Fig. 7. Isoperimetrical view of engineering blade and ballistic package a) together with the coarse area, b) without coarse area

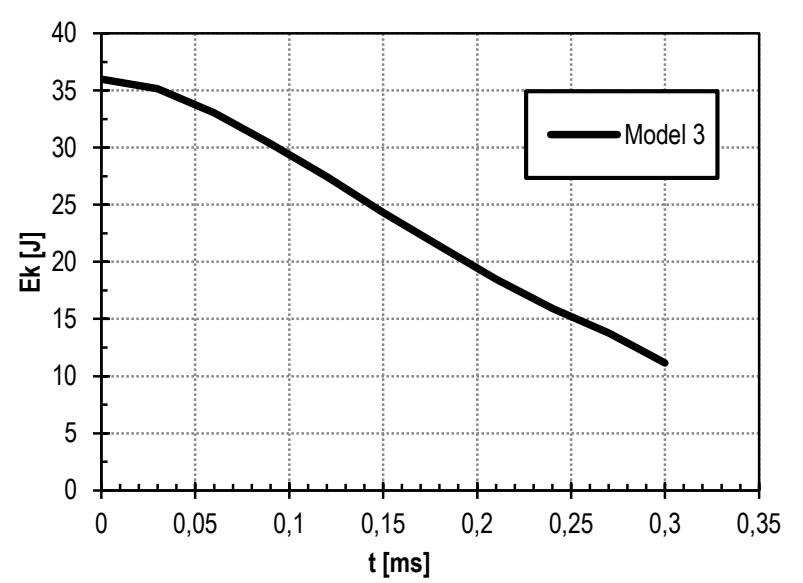

Fig. 16. Kinetic energy of blade in model 3

Fig. 16 shows kinetic energy of the blade. The chart is continuous, no abrupt changes of the kinetic energy descent are observed. It means that the contact model worked properly in the first instant of time. In other words, the contact has been properly established.

During eroding of the elements, successive elements smoothly came into contact with the knife and kept it propped. Energy was dissipated to work against the forces of elasticity of the material of the package and eroding elements.

At $t=0.0003 \mathrm{~s}$ kinetic energy of the blade dropped to the level of approximately $11.16 \mathrm{~J}$. 


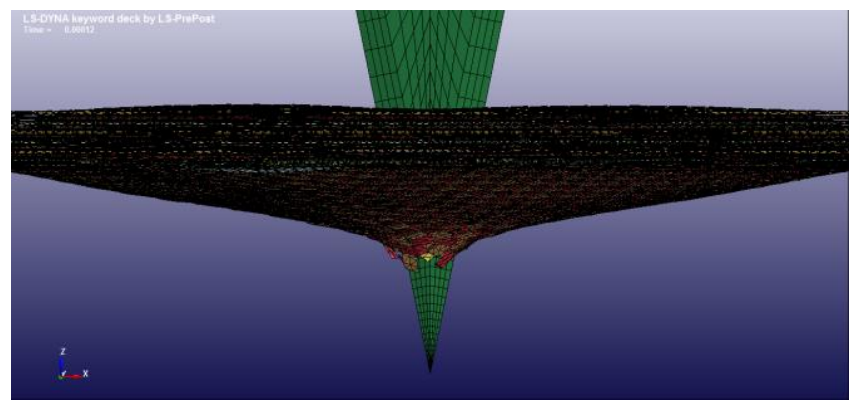

Fig. 8. Ballistic package punctured by blade in time $t=0.0001 \mathrm{~s}$

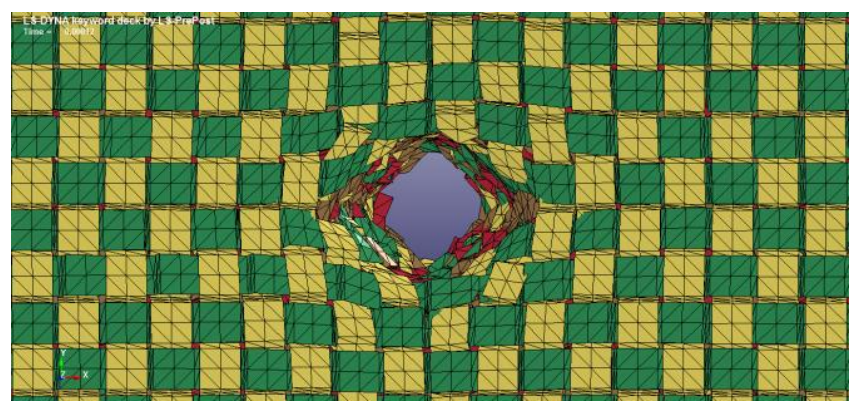

Fig. 9. Ballistic package punctured by blade $t=0.0001 \mathrm{~s}-$ top view

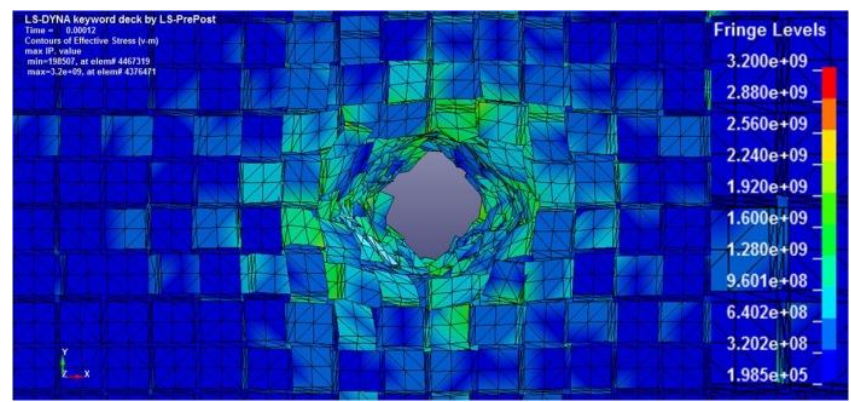

Fig. 10. Equivalent tensile stresses in the ballistic package $t=0.0001 \mathrm{~s}$ - top view

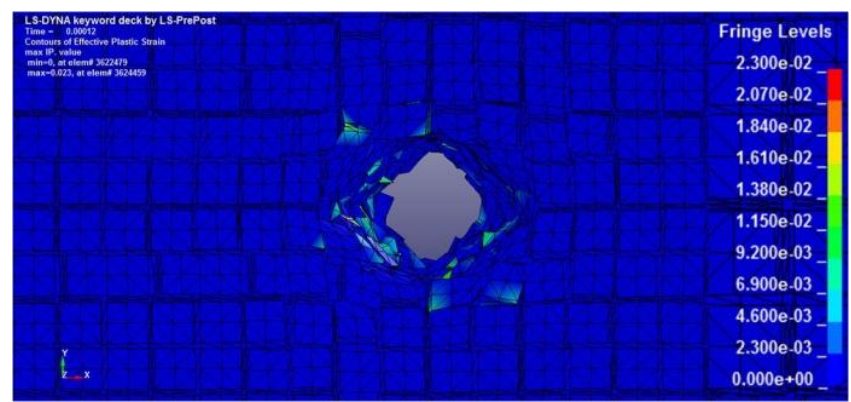

Fig. 20. Plastic strains in ballistic package $t=0.0001 \mathrm{~s}-$ top view

Fig. 21 summarizes kinetic energy from the individual tests. It can be observed, that the energy graph for model 3 for the entire analyzed time is the lowest. The kinetic energy of model 2 in the middle range of time corresponds to the energy of model 3 and next coincides with the value of the first model. Kinetic energy graph for model 1 has the lowest dissipation of energy in almost the entire range of time and only at the last moment coincides with the graph of the second model.

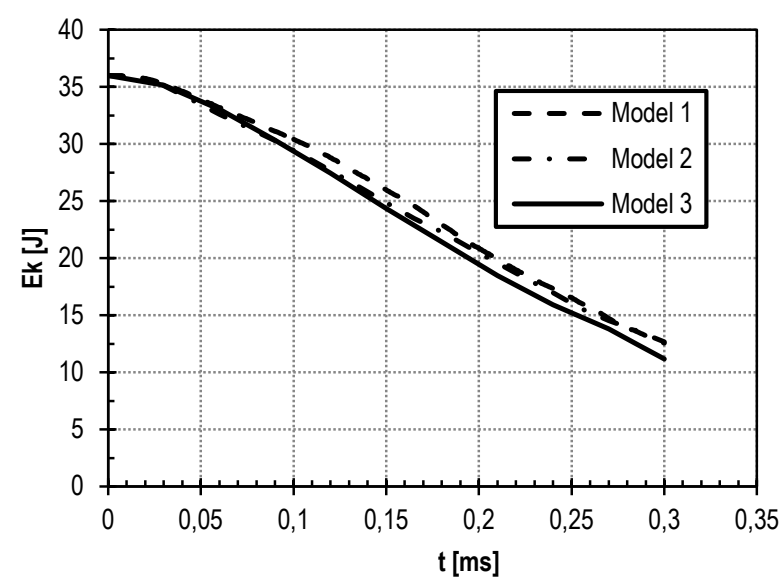

Fig. 21. Summary of kinetic energy of individual models

\section{CONCLUSIONS}

On the basis of three models, in which three ways of layers arrangement of a ballistic package were modeled, there have been drawn the following conclusions:

The largest energy dissipation was obtained in a model in which there was used aramid fabric made of Kevlar 49, the coefficient of friction $\eta=0.1$ and the orientation of fibers: 0 degrees, 22.5 degrees, 45 degrees and 67.5 degrees.

The presented models show that the lowest energy dissipation is obtained when fabrics were arranged in the same direction (all plies arranged the same).

Maximum energy dissipation is obtained when fabrics are arranged at different angles (model 3). It results from evenly stiffness of the ballistic package around the blade, what causes an evenly strain of the package material.

The coefficient of friction between the bundles of the ballistic package was assumed by the author of the work, due to lack of references in the literature. It means that-determination of the coefficient of friction will require laboratory testing. However, controlling the value of the coefficient of friction gives a promising outlook for the future.

\section{REFERENCES}

1. Barauskas R. (2007), Multi-Scale Modelling of Textile Structures in Terminal Ballistics, 6th European LS-DYNA Users' Conference, 4.141-4.154.

2. Ha-Minh C., Imad A., Kanit T., Boussu F. (2013), Numerical analysis of a ballistic impact on textile fabric, International Journal of Mechanical Sciences, 32-39.

3. Horsfall I. (2000), Stab Resistant Body Armour, Cranfield University, Engineering Systems Department Submitted For The Award Of PhD.

4. Johnson A., Bingham A., G., Majewski E. C. (2012), Establishing the performance requirements for stab resistant Additive Manufactured Body Armour (AMBA), The 23 Annual International Solid Freeform Fabrication (SFF) Symposium, 297-306.

5. Jones R. M. (1999), Mechanics of composite materials, Taylor \& Francis Inc.

6. Livermore Software Technology Corporation, Modeling of Composites in LS LS-DYNA.

7. LS-DYNA, (2006), Teory Manual.

8. LS-DYNA, (2007), Keyword User Manual. 
9. Nilakantan G., Keefe M., Gillespie J. W. Jr., Bogetti T. A. (2008), Novel Multi-scale Modeling of Woven Fabric Composites for use in Impact Studies, 10th European LS-DYNA Users' Conference, 20-19-20-38.

10. Nilakantan G., Keefe M., Gillespie J. W. Jr., Bogetti T. A., Adkinson R. (2009), A Study of Material and Architectural Effects on the Impact Response of 2D and 3D Dry Textile Composites using LS-DYNA, 7th European LS-DYNA Users' Conference, 1-16.

11. Nilakantan G., Keefe M., Gillespie J. W. Jr., Bogetti T. A., Adkinson R., Wetzel E. D. (2010), Using LS-DYNA to Computationally Assess the V0-V100 Impact Response of Flexible Fabrics Through Probabilistic Methods, 11th European LS-DYNA Users' Conference, 5-1 - 5-12.

12. U.S. Department of Justice (2000), Stab Resistance of Personal Body Armor NIJ Standard-0115.00, National Institute of Justice.

13. Zacharski S. E. (2010), Nonlinear mechanical behavior of automotive airbag fabrics: an experimental and numerical investigation, The University Of British Columbia. 